\title{
Impedance Spectroscopy of Synthetic Proustite at High Pressures
}

\author{
N. V. Melnikova, A. N. Babushkin, O. L. Kheifets, and K. V. Kurochka \\ Ural Federal University, Yekaterinburg, 620000 Russia \\ e-mail:nvm.melnikova@gmail.com
}

\begin{abstract}
The effect of high pressure (up to $40 \mathrm{GPa}$ ) and alternating electric field frequency $(100 \mathrm{~Hz}-500 \mathrm{kHz})$ on the electrical properties of synthesized single-crystal proustite $\mathrm{Ag}_{3} \mathrm{AsS}_{3}$ is studied. The behavior of real and imaginary parts of impedance upon an increase in pressure confirms earlier data on the closing of valence and conduction zones, and on the material's transition to the metal state at $\sim 30 \mathrm{GPa}$.
\end{abstract}

DOI: $10.3103 / \mathrm{S} 1062873813030271$

\section{INTRODUCTION}

The unique physical properties of crystalline proustite $\left(\mathrm{Ag}_{3} \mathrm{AsS}_{3}\right)$ (e.g., its ionic conductivity, variations in heat capacity at low temperatures, phase transitions, optical and acoustic characteristics, and ferroelectric properties) allow us to apply it in acoustooptical, optoelectrical, electroacoustic, and other devices $[1-4]$. The external effect on proustite properties, i.e., the material functioning with variation in external parameters, is of theoretical and practical interest. The aim of this work was to study the effect of high pressures (up to $40 \mathrm{GPa}$ ) on complex impedance, complex conductivity, and the loss tangent of proustite $\mathrm{Ag}_{3} \mathrm{AsS}_{3}$, and to estimate the level of pressure that ensures the transition from semiconductive type of conductivity to metallic conductivity.

\section{EXPERIMENTAL}

Proustite $\left(\mathrm{Ag}_{3} \mathrm{AsS}_{3}\right)$ monocrystals were grown via vertical melt crystallization using the StockbargerBridgman approach on a device that allowed a constant gradient of the temperature field. Use of this device enabled us to obtain the necessary growth rates for monocrystals and to select the optimum parameters affecting material purity and quality. The monocrystals were grown in two modes: moving of container through the melting zone and gradually lowering the temperature under a constant gradient of the temperature field. The ampoule filled with material was therefore slowly moved inside the vertical furnace. The furnace's maximum temperature was $50-100^{\circ} \mathrm{C}$ higher than the material's melting temperature, and the melt was homogenized in that zone in the ampoule. The temperature gradient, created artificially with the help of additional heaters, ensured nucleation.

In conditions of the atmospheric pressure and of the room temperature proustite has a hexagonal ele- mentary cell (space group $3 R c, a=1.076 \mathrm{~nm}$, and $c=$ $0.885 \mathrm{~nm}$ ). According to our data on $\mathrm{Ag}_{3} \mathrm{AsS}_{3}, \mathrm{AgAsS}_{2}$, and $\mathrm{Cu}_{3} \mathrm{AsS}_{3}$ compounds, all of them are characterized by similar features of crystalline structure: arsenic atoms are found at the top of trigonal pyramids with sulfur atoms at their bases. The presence of the pyramidal complexes $\left(\mathrm{AsS}_{3}\right)$ allows to consider these compounds (and their numerous analogues) as an individual class of materials termed sulfosalts. Chemical bond in the $\mathrm{AsS}_{3}$ complex is purely covalent. Silver (copper) ions in sulfosalts are associated with the pyramidal complexes by relatively weak ionic bonds. Such complicated chemical bonding controls many of the physical properties of the considered materials, particularly the substantial ion transfer in proustite $\left(\mathrm{Ag}_{3} \mathrm{AsS}_{3}\right)$ and smithite $\left(\mathrm{AgAsS}_{2}\right)[3,5]$. The structural formulas of the compounds distinguished by the existence of pyramidal complexes such as $\mathrm{AsS}_{3}$ in their structure should be given in a form emphasizing their crystallochemical features. The proustite structural formula can be given as $\mathrm{Ag}_{3}^{+}\left[\mathrm{As}^{\uparrow \uparrow \uparrow} \mathrm{S}_{3}^{\downarrow}\right]^{-}$. The proustite crystalline structure (Fig. 1) is based on $\mathrm{AsS}_{3}$ pyramidal groups and $\mathrm{Ag}_{2} \mathrm{~S}$ spiral chains. The $\mathrm{AsS}_{3}$ pyramids are aligned along a polar three-fold axis $c$ (pyramid bases

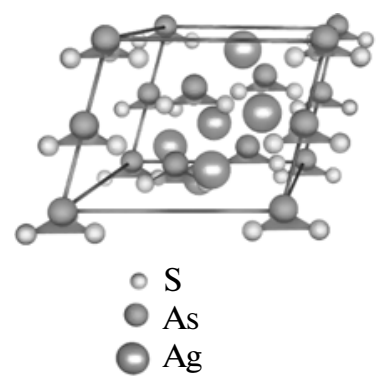

Fig. 1. Schematic view of proustite hexagonal cell. 


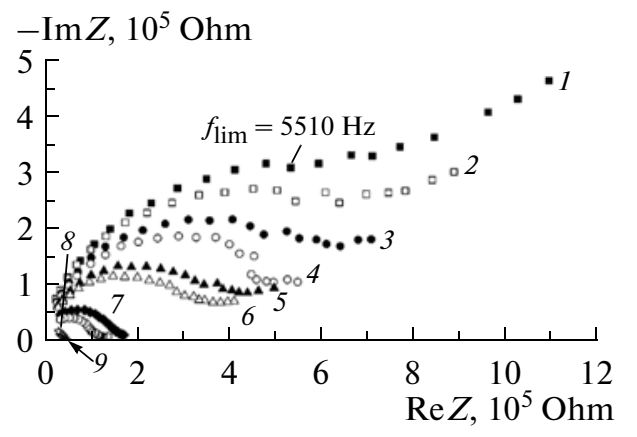

Fig. 2. Impedance spectra of the cell with $\mathrm{Ag}_{3} \mathrm{AsS}_{3}$ at different pressures (GPa): (1) 9, (2) 14, (3) 16, (4) 19, (5) 20, (6) 22, (7) $23,(8) 24$, (9) 25.

are perpendicular to the third order axis of elementary cell) and are related to one another through the slip plane $c$. Silver atoms are distributed among the pyramids and join the $\mathrm{AsS}_{3}$ complexes through ionic $\mathrm{S}-$ $\mathrm{Ag}-\mathrm{S}$ bonds forming two sets of spirals (right- and left-handed) parallel to axis $c$.

A pressure of 8-40 GPa was attained in the highpressure chamber (HPC). The chamber was equipped with synthetic diamond (black carbon) anvils, good conductors that allowed us to study the electrical properties of the samples placed in the HPC [6]. The measurement error was $5 \%$. The electrical properties over the pressure interval were studied via impedance spectroscopy using a RLC-2000 impedance analyzer and Solartron 1260A universal frequency response analyzer. The accuracy of electrical resistance was $0.1 \%$. The baric dependences of electric conductivity, the real and imaginary parts of impedance, and the loss tangent were studied at stable frequencies of alternating voltage in the area where effect of electrode processes could be ignored. The electric conductivity value was estimated from the real part of admittance $(\operatorname{Re} Y)$, while the loss tangent was calculated from the measured real $(\operatorname{Re} Z)$ and imaginary $(\operatorname{Im} Z)$ parts of impedance using the formula $\tan \delta=-\operatorname{Re} Z / \operatorname{Im} Z$.

\section{RESULTS AND DISCUSSION}

The impedance hodographs of the cell with $\mathrm{Ag}_{3} \mathrm{AsS}_{3}$ sample at different pressures are presented in Fig. 2. The frequency dependences of impedance (Fig. 2) and admittance are characterized by two clearly separate (by boundary frequency, $f_{\mathrm{b}}$ ) high- and low-frequency parts. The high-frequency parts of the impedance hodographs are approximated by arcs passing through the origin of the coordinates, and characterize the sample properties; the low-frequency parts characterize the electrode impedance effect. This form of hodograph is characteristic for materials

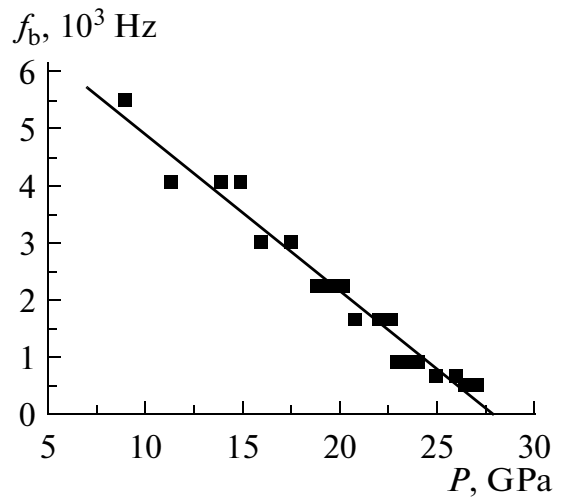

Fig. 3. The boundary frequency-pressure dependence.

with ionic electrotransport. An increase in pressure is accompanied by decrease drop in circle radii, while the frequency ranges containing hodograph's branches associated with the electrode processes are displaced toward the low frequencies. At pressures exceeding $27 \mathrm{GPa}$, the impedance hodographs show only the branches characterizing the sample properties. Variations in a form of hodographs upon an increase in pressure are indicative of increase in conductivity and a drop in the boundary frequency.

Approximating the boundary frequency-pressure relation via the linear function (Fig. 3 ) allows us to determine the pressure level $(\sim 28 \mathrm{GPa})$ at which the electrode processes in the near-electrode layers of the sample stop playing an important role even at low frequencies; i.e., the real part of complex conductivity $(\operatorname{Re} Y)$ and complex resistance $(\operatorname{Re} Z)$ of the cell with the $\mathrm{Ag}_{3} \mathrm{AsS}_{3}$ sample is controlled by material properties under a constant current over the investigated range of frequencies; $\operatorname{Re} Y$ and $\operatorname{Re} Z$ correspond to the material's conductivity on a direct current and resistance to a direct current at pressures exceeding $28 \mathrm{GPa}$. The shape of the hodographs at pressures of over $30 \mathrm{GPa}$ is indicative of the existence in an equivalent scheme modeling the sample cell connected in series resistance of electrodes (which is very low in our case) and purely active resistance corresponding to material resistance that could be due to a possible transition to metallic-type conductivity at pressures of 28-30 GPa. The pressure ensuring a transition from a semiconductor- to a metal-type conductivity-temperature dependence was estimated from the pressure value such that the imaginary part of impedance was zero. The pressure dependences of the real part of conductivity $\operatorname{Re} Y(P)$ and of loss tangent $\tan \delta(P)$ upon an increase in pressure were approximated by rising exponential functions: $\operatorname{Re} Y=q(P)=\operatorname{Re} Y_{0}+a e^{\frac{P}{P_{0}}}$ and 


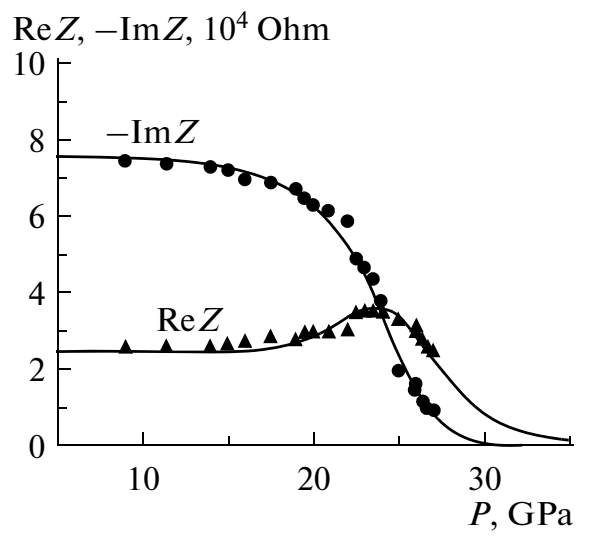

Fig. 4. Baric dependences of the real and imaginary parts of impedance $\left(\operatorname{Re} Z\right.$ and $\operatorname{Im} Z$ ) of the cell with $\mathrm{Ag}_{3} \mathrm{AsS}_{3}$ upon an increase in pressure. Alternating voltage frequency, $f=200 \mathrm{kHz}$. The dots represent experimental data and the solid lines represent calculations.

$\tan \delta=f(P)=B_{0}+b e^{\frac{P}{P_{0}}}$. Having expressed the real and imaginary parts of impedance from the system relating $\operatorname{Im} Z(P), \operatorname{Re} Z(P), \tan \delta(P)$, and $\operatorname{Re} Y(P)$ in terms of loss tangent and the real part of complex conductivity, we found our approximation of $\operatorname{Im} Z(P)$ and $\operatorname{Re} Z(P)$ at a given frequency:

$$
\begin{gathered}
\left\{\begin{array}{c}
\frac{\operatorname{Re} Z}{\operatorname{Re}^{2} Z+\operatorname{Im}^{2} Z}=\operatorname{Re} Y(P)=q(P) \\
\frac{\operatorname{Re} Z}{\operatorname{Im} Z}=-\tan \delta(P)=f(P)
\end{array}\right. \\
\Rightarrow \operatorname{Re} Z=\frac{f^{2}(P)}{q(P)\left(f^{2}(P)+1\right)}, \\
-\operatorname{Im} Z=\frac{f(P)}{q(P)\left(f^{2}(P)+1\right)} .
\end{gathered}
$$

Figure 4 presents the curves of experimental (dots) and approximated (solid lines) dependences of $\operatorname{Re} Z(P)$ and $-\operatorname{Im} Z(P)$ at $200 \mathrm{kHz}$. In the approximated dependences, the imaginary part of impedance becomes almost zero at $30 \mathrm{GPa}$ irrespective of frequency. According to the authors of [7], who investigated the high pressure effect on the thermoelectric properties and electrical characteristics of proustite in constant electric fields, the valence and conductivity bands overlap and the semiconductive resistance dependence becomes metallic at $30 \mathrm{GPa}$ exactly. The thermal electromotive force (EMF) of proustite below $28 \mathrm{GPa}$ has a sign corresponding to hole-type conductivity (at normal pressures, the proustite electric conductivity depends $99 \%$ on silver ions and $1 \%$ on holes). The thermal EMF estimate (at pressures of over $30 \mathrm{GPa}$ ) yielded $2 \mathrm{eV}$ for the chemical potential of charge carriers and $13 \times 10^{23} \mathrm{~cm}^{-3}$ for concentrations of charge carriers (electrons). The pressure coefficient of the proustite direct band gap under relatively low pressures is $9 \times 10^{-11} \mathrm{eV} \mathrm{Pa}^{-1}$ [8]. If we assume that this coefficient remains unchanged up to the investigated pressure interval, the conductivity activation energy under $20 \mathrm{GPa}$ (at direct transitions) ought to be $0.18 \mathrm{eV}$ (at a band gap width under zero pressure of $2.156 \mathrm{eV})$. The experimental activation energy value at $20 \mathrm{GPa}$ is $0.22 \mathrm{eV}$ [7]. Similar calculated and experimental values of the conductivity activation energy assume that proustite's conductivity is due to interband transitions under $20 \mathrm{GPa}$ and $77-300 \mathrm{~K}$. At pressures exceeding $30 \mathrm{GPa}$, the EMF sign changes, indicating the electrical conductivity of a metal-like phase in this pressure interval. Upon variations in pressure of 30 to $40 \mathrm{GPa}$, the EMF value remained unchanged, reaching $7.9 \mu \mathrm{V} \mathrm{K}^{-1}$ [7]. Having studied the effect of a maximum hydrostatic pressure of $2.6 \mathrm{GPa}$ on the optical properties of proustite and nuclear quadrupole resonance spectra, the authors of [9] estimated the pressure value ensuring the transformation of proustite into metal at $25 \mathrm{GPa}$. At the indicated pressure a maximum on the baric dependence of $\operatorname{Re} Z$ was observed (Fig. 4). The maximum could be related to the saturation of trap centers upon an increase in the number of carriers with pressure growth [10]. Pressures of over $25 \mathrm{GPa}$ ensure a rapid rise in conductivity and drops in $\operatorname{Re} Z$ and $\operatorname{Im} Z$. In the case of a drop in pressure, the electric characteristics are reversible, and hysteresis is observed.

Approximation to the zero value of the imaginary part of impedance thus allows us to estimate the level of pressure (particularly for proustite) that ensures the closing of valence and conductivity zones and the transition from a semiconductive to a metal-type conductivity dependence.

\section{CONCLUSIONS}

It was established that the electric properties of proustite under high pressures and an alternating current agree with investigation data for a direct current. We estimated the pressure value that ensures a transition from a semiconductive to a metal-type conductivity dependence using a linear approximation of the boundary frequency-pressure dependence and approximating the imaginary part of impedance to zero.

\section{ACKNOWLEDGMENTS}

The work was partially supported by the federal target program Scientists and Science Teachers of an Innovative Russia, 2009-2013; by the Ural Federal University Program for the Financial Support for Young Scientists; and by the Russian Foundation for Basic Research, project no. 10-02-96036. 


\section{REFERENCES}

1. Zlokazov, V.B., Babushkin, A.N., and Kobelev, L.Ya., Fiz. Tverd. Tela, 1983, vol. 25, no. 2, p. 573.

2. Gorin, Yu.F., Babushkin, A.N., and Kobelev, L.Ya., Pis'ma Zh. Eksp. Teor. Fiz., 1985, vol. 41, p. 112.

3. Gagor, A., Pawlowski, A., and Pietraszko, A., J. Solid State Chem., 2009, vol. 182, p. 451.

4. Schonau, K.A. and Redfern, S., J. Appl. Phys., 2002, vol. 92, no. 12, p. 15.

5. Zlokazov, V.B., Kobelev, L.Ya, and Korpachev, S.V., Dokl. Akad. Nauk SSSR, 1981, vol. 259, no. 2, p. 344.

6. Vereshchagin, L.F., Yakovlev, E.N., Vinogradov, B.V., et al., High Temp. - High Press., 1974, vol. 6, p. 499.
7. Babushkin, A.N and Zlokazov, V.B., Fiz. Tverd. Tela, 1990, vol. 32, no. 8, p. 2490.

8. Mikheev, V.N., Rentgenometricheskii opredelitel' mineralov (Roentgenometry Guide of Minerals), Moscow: Gos. Nauch.-tekhn. izd. lit. po geologii i okhrane nedr, 1957.

9. Gerzanich, I., Dobranskii, S.A., Golovei, M.I., et al., in Sbornik nauchnykh trudov VNII monokristallov (AllRussian Scientific Research Institute of Monocrystals: Collection of Scientific Papers), Kharkov, 1978, p. 62.

10. Solanki, G.K., Patel, P.D., Agarwal, M.K., et al., High Press. Res., 2001, vol. 21, p. 15. 